\title{
PARA UNA TIPOLOGÍA DE LOS PROCEDIMIENTOS METAFICCIONALES EN LA LÍRICA CONTEMPORÁNEA
}

\author{
José Antonio Pérez Bowie \\ Universidad de Salamanca
}

El término metaficción remite a dos contenidos que no son excluyentes, sino complementarios: uno, la puesta en evidencia del carácter ficcional de la comunicación literaria, que se efectúa desde el interior del propio discurso; el otro, la autorreferencialidad o la reflexión que sobre sí mismo emprende el discurso, convirtiéndose en un metalenguaje. Ambos contenidos están, como apunto, claramente imbricados en cuanto la denuncia de la ficcionalidad puede convertirse en el punto de partida para una reflexión metateórica, o viceversa, esta última puede conducir a la mostración de los mecanismos productores de ficcionalidad.

En el caso de la lírica contemporánca la presencia de lo metaficcional en su doble vertiente adquiere una importancia nada desdeñable, convirtiéndose tanto en expresión de la impotencia frente a un lenguaje degradado por el Poder ( $y$, consiguientemente, como un acto de rebeldía que persigue el desenmascaramiento del mismo) como en una manifestación del carácter ficcional de la realidad representada; el reflejo de ésta deja de ser el tema del texto lírico para cargar el acento sobre la representación misma como tal representación, sobre la ficción como tal (BOUSOÑO, 1983: 54). De hecho, ambas vertientes son apuntadas como rasgos fundamentales de lo que se ha dado en llamar postmodernidad por parte de los estudiosos de las corrientes artísticas que se entrecruzan y superponen configurando el complejo panorama de la cultura de nuestro siglo. Así, Matei Calinescu, quien alude a la autorreferencialidad y a la metaficción como las dos vías a las que recurre la obra postmodernista "para dramatizar la inescapable circularidad" (CALINESCU, 1991: 293). 


\section{JOSÉ ANTONIO PÉREZ BOWIE}

Fn aras de una mayor claridad, pueden emplearse los términos de metaficción y metapoesía; yo me circunscribiré al análisis del fenómeno que designa el primero de ellos, es decir, al cuestionamiento que de la ficción se hace desde el interior del propio discurso que la genera y que en el terreno de la poesía consiste fundamentalmente, como podremos comprobar, en la transgresión de los esquemas sobre los que se sustenta la comunicación lírica.

Un includible paso previo antes de abordar el análisis de los mecanismos mediante los que se lleva a cabo el euestionamiento de la fieción desde el interior del poema ha de ser el de exponer algunas reflexiones en torno al carácter específico de la ficcionalidad del texto lírico, que, por otra parte, dista mucho de ser admitida de modo unánime por los estudiosos del fenómeno.

Quienes se han aproximado a él desde una metodología estrictamente pragmática no tienen ningún reparo en englobar el poema, como cualquier otro tipo de comunicación literaria, dentro de los límites de lo fiecional. El poema no es para ellos sino la imitación intencionada de una serie de actos de habla que, de hecho, no tienen otra forma de existencia: el autor imita los actos de habla de un hablante imaginado y el lector imita o evoca una situación imaginaria, la descrita por el hablante imaginado (S. LEVIN, 1987: 66-67). El mecanismo de asunción de esa comunicación por parte del lector ha sido explicada por L.evin a partir de la presuposición de una frase matriz subyacente en la estructura profunda de todo poema y formulable en los siguientes términos: Yo me imagino a mi mismo en y te invito a concebir un mundo en que...; en tal mundo ya no es el pocta quien actúa, sino una proyección de sí mismo, su personaje; y si la invitación fuese aceptada por el lector se producirá en él un acuerdo tácito que le llevará a contemplar el mundo presentado como exclusivo producto del acto imaginativo del poeta y en el que las condiciones de verdad quedan en suspenso (S. I.F:VIN, 1987: 71-73). $\Lambda$ I conjugarse las fuerzas ilocutivas de las dos partes de la oración dominante, dice Levin, se produce en el lector el efecto perlocutivo consistente en la suspensión de la incredulidad que constituye la fe poética. O como apunta Schmidt, "reconocer la fictivización de los papeles comunicativos del productor y del receptor lleva a no verse en la obligación de referir los mundos textuales al marco de referencia de los modelos válidos para el productor real y el receptor real" (SCHMIDT, 1987: 206). Eil discurso poético, al no ser, pues, un acto de habla individual, sino la representación de dicho acto, no puede verse afectado por la interrelación entre poeta y público, de ahí que su forma sea definitiva, lo que garantiza su repetición sin restricciones (OOMEN, 1987: 148). Una ajustada y esclarecedora defensa del carácter ficcional de la comunicación lírica puede, asimismo, verse en un reciente trabajo de José M. ${ }^{2}$ Pozuelo, de ineludible lectura, al que remito (POZUELO, 1991).

Desde otras perspectivas, puede, en cambio, llegar a predicarse el carácter por excelencia realista de la poesía lírica frente a los otros géneros literarios, como hace, por cjemplo, Combe, quien se apoya en "la intensa identificación que posibilita entre la vivencia del lector y la emoción representada" (VILLANUEVA, 1992: 187). Por ello sostiene que la poesía se define por la apertura de su horizonte referencial, mientras que la narración lo cierra en el mundo imaginario propio que instaura: frente a la autorreferencialidad de esta última, la poesía se caracterizará, entonces, por su referencialidad.

En el mismo sentido se pronuncia Käte Hamburger al afirmar que el poema lírico es un enunciado de realidad en la medida en que remite precisamente al único sujeto de la enunciación lírica: el lector no ve en los enunciados del poema una ficción, una ilusión, sino que aprehende el poema como una reexperiencia; si quicre comprender el poema, tiene que interrogarse, pues se encuentra ante las manifestaciones de un otro real, de un Tú que habla a un Yo, sin intermediario, sólo la palabra. De ahí, dirá que, aunque la experiencia sea ficticia, en 
el sentido de invención, el sujeto de la experiencia, y con él, el sujeto de la enunciación, el yo lírico, no pueden ser más que reales (HAMBURGER, 1986: 237).

Otra defensora del carácter no ficcional del texto lírico es Susana Reisz. de Rivarola, quien, apoyándose en teóricos como Sticrle y Landwehr, sostiene que un texto sólo puede catalogarse como ficcional si en su desviación de las reglas lingüísticas y pragmáticas vigentes se lo acepta como constitución de una nueva realidad; cosa que no sucede en gran parte de la lírica contemporánea que, si bien puede ser caracterizada como desviante, no se la puede relacionar con ningún mundo posible: los poemas suelen ser construcciones que se designan a sí mismas, sin remitir a un correlato poético (REISL, 1989: 202-203). Por otro lado, defiende la posibilidad de entender ciertos enunciados líricos como actos de habla del propio autor, "manifestaciones directas de su real sentir en el momento de escribir el poema"; todos los recursos de éste "no serán, pues, señales de la existencia de una voz ficticia, sino expresión estética, no mediatizada, de cierta visión del mundo, marcas distintivas de un discurso no pragmático y sin interlocutor definido pero que, a pesar de ello, forma parte del aquí y del ahora de la situación de escribir" (REIS\%, 1989: 209-210). Por ello, siguiendo a Landwehr, traza la frontera entre ficción y no fieción en el hecho de que el texto pueda o no, en su desviación de las reglas lingüísticas y pragmáticas vigentes, ser aceptado como constitución de una nueva realidad; si tan sólo se lo caracteriza como desviante, sin que pueda relacionárselo con ningún mundo posible, scría no ficcional (REISZ, 1989: 214).

Sin desdeñar estos argumentos en contra de la fíccionalidad del texto lírico, pienso que resulta factible seguir utilizando el término metaficción si lo empleamos para referirnos a las rupturas o transgresiones que el texto presenta con respecto a los moldes convencionales por los que se rige la comunicación lírica; ésta ha estado sometida a lo largo de la historia a una fuerte convencionalización que ha afectado tanto al enunciado (estructuras lingüísticas) como a las condiciones de la enunciación (marco pragmático) y que le confiere un estatuto de irrealidad perfectamente perceptible; piénsese, por ejemplo, en las diversas máscaras que adopta el sujeto de la enunciación para marcar las distancias con relación al yo autorial y que van desde los estereotipos del siervo de la poesía cortesano-trovadoresca o del pastor de la lírica renacentista a los heterónimos inventados por algunos poetas de nuestro siglo. En la experiencia de los receptores no existen, pues, dudas en adscribir la situación comunicativa del poema al ámbito de la irrealidad y en admitir, por consiguiente, su pertenencia a la categoría de lo ficcional. De ahí, entonces, que resulte posible echar mano del concepto de metaficción para describir aquellos procedimientos a los que la lírica contemporánea recurre muy a menudo para denunciar ese carácter ficcional, para desrealizar la comunicación poemática, presentando sus enunciados desvinculados de la personalidad del yo histórico del autor y poniendo de relieve la teatralidad de la situación comunicativa del poema, su carácter de ficción representada y contemplada como tal. Esa insistencia en la mostración del artificio ha sido apuntada por Calinescu como otro de los rasgos definidores de la cultura postmoderna: no se trata ya, dirá, de mostrar las convenciones y recursos utilizados en la construcción de la obra de arte, como comenzó haciendo el modernismo, sino que ahora, al mostrarlos, "establece que todo lo demás es artificio y que simplemente no hay escapatoria" (CALINISCU, 1991: 292).

Centrémonos ahora, partiendo de la revisión de un conjunto de textos pertenecientes a las últimas generaciones de líricos españoles, en la descripción y el análisis de los procedimientos más usuales mediante los que se lleva a cabo esa puesta en evidencia de la ficción poemática. 


\section{JOSÉ ANTONIO PÉREZ BOWIE}

\section{a) Utilización de la primera persona ajena}

Es la denominación que Yuri l. Levin emplea para referirse a aquellos sujetos de la enunciación lírica totalmente inidentificables con el yo del autor (Y. LEVIN, 1979); sus manifestaciones a lo largo de la historia de la poesía son muy diversas, pues van desde el personaje mitológico erigido en sujeto enunciador o el yo difunto de muchos poemas elegiacos al animal u objeto inanimado a quienes el autor confiere en ocasiones la responsabilidad de la enunciación (caso este último menos frecuente por la dificultad, apuntada por Levin, de construir a partir de un yo explícito tan inusitado la imagen del yo implícito sobre la que se sustentan los mecanismos identificadores que garantizan el funcionamiento de la comunicación). En la poesía clásica, la recurrencia a este procedimiento resultaba perfectamente asumible como consecuencia de la poderosa convencionalización a que estaban sometidos los subgéneros que lo emplean (lírica mitológica y lírica funeraria, primordialmente)'; y en cl Romanticismo suele ser expresión de la necesidad de proyectar un ego sobredimensionado sobre una imagen hiperbólica, lo que trae como consecuencia la creación de un sujeto enunciador desmesurado muy distante de la realidad biográfica del autor (piénsese, por ejemplo, en el yo explícito de muchos de los poemas de Espronceda). En cambio, en la lírica de nuestros días, responde al radical distanciamiento que el autor establece entre él y el enunciado textual y que, en definitiva, es expresión del deseo antes mencionado de evidenciar el carácter teatral (ficción representada) de la enunciación. Lo que, con palabras de Bousoño, describiríamos como la "simultaneidad de la representación y del desenmascaramiento del mismo acto de representar" (BOUSOÑO, 1983: 54). Langbaum explica cómo muchos de los poemas contemporáneos han de ser concebidos como un auténtico monólogo dramático, como un proceso mediante el cual la experiencia que el poeta revela está contada por un observador, hablante o personaje, de una acción dramática que no es necesariamente el poeta y "que ha sido dotado por éste de las cualidades necesarias para que el poema suceda" (MANGINI, 1980: 73). La recurrencia a una primera persona ajena, a la que se instituye como yo explícito responsable de la enunciación, puede ser considerado un caso límite de monólogo dramático.

\section{Yo histórico}

Es la manifestación más evidente, por explícita, del fenómeno y aparece con relativa frecuencia en la lírica de nuestra época; consiste en la recurrencia como sujeto de la cnunciación a un personaje histórico a quien el autor cede su voz para, en un juego culturalista, activar ese pasado apoyándose en el distanciamiento irónico que impone la perspectiva cronológica acumulada. No obstante, no resulta aventurado apuntar la presencia de un cierto tono de melancolía suscitado por la evocación de un tiempo ido, pues aunque la teatralidad con que se rodea la reconstrucción de la escena actúa como filtro contra el sentimentalismo, es posible percibir una corriente de afecto en el yo implícito que elaboramos a partir del hablante lírico; téngase en cuenta que tales personajes, cuyo pensamiento y sentimentalidad guardan

1.- Fn la lírica de carácter funerario garantizaba su aceptabilidad la convención del epitafio como un mensaje póstumo del difunto, el cual aparece como sujeto de la enunciación; en la poesía de tipo mitológico, por su pante, la concepción de temas y motivos de la Antigüicdad como elemento distanciador de la expresión sentimental hacía perfectamente admisible la atribución del mensaje a un personaje de la historia o la mitología clísicas (PÉRL:/, BOWII:, 1993). 


\section{TIPOI OGÍA DE LOS PROCEDIMIENTOS METAFICCIONAI.ES FN LA LÍRICA}

amplias similitudes con los del autor, son elegidos por éste a modo de correlatos objetivos (BOUSOÑO, 1983: 36)2.

Entre los muchos títulos que podrían citarse como cjemplificación de este procedimiento están "Maquiavelo en San Casciano", de José Ángel Valente; "En la República de Platón", de Francisco Brines; "El armero Juan Martín lamenta el destino de una pieza magistral", de Carlos Barral; "Giacomo Casanova acepta el cargo de bibliotecario que le ofrece, en Bohemia, el conde de Woldstein", de Antonio Colinas; "Ludwig Van Beethoven piensa antes de interpretar por última vez", de Jaime Siles, o "Trotski medita en Coyoacán", de Marcos Ricardo Barnatán. Véase un fragmento del poema de Valente:

Al tordo que madruga en los olivos tiendo tempranas redes, mientras dura setiembre $\mathrm{y}$ un cielo gris apaga el eco doble de esta pena en pobreza y desticrro.

Tengo un bosque

cuya madera hago talar, pues de tan poca riqueza me sustento.

Los negocios de la República y los reyes de España y Francia o cl Gran Duque lejos están; mas bueno fuera que alguien pagase en este tiempo aquel saber de entonces ${ }^{3}$.

\section{Yo irónico}

La imposibilidad de la identificación entre el sujeto de la enunciación poemática y el yo autorial estribaría, en este caso, en la radical incompatibilidad que el lector percibe entre las palabras pronunciadas por aquél y la trayectoria ideológica de éste. El enunciado proferido por el yo lírico actúa en tales casos a modo de lítotes, ya que se presenta invertido en un juego irónico el sentido del mensaje del yo autorial. Un ejemplo sumamente ilustrativo de este mecanismo distanciador puede ser el poema de Ángel González "Discurso a los jóvenes", procedente de su libro Sin esperamza, con convencimiento, del que transcribo algunos fragmentos:
De vosotros, los jóvenes, espero no menos cosas grandes de las que realizaron vuestros antepasados.
Os entrego

2.- El procedimiento, por lo que tiene de puesta en escena y por su subsiguiente capacidad de actuar como filtro del sentimentalismo, aparece con cierta frecuencia en la lírica de otros períodos y culturas. Pueden aducirse, como ejemplo, el soneto de Quevedo "Funeral discurso de Anníbal tomando el veneno para morir, viéndose viejo, solo y desterrado" o el poema de Kavafis que lleva por título "Melancolía de Jasón hijo de Cleandro, poeta de Komagene".

3.- Punto cero (Poesía 1953-1979), Barcelona, Seix Barral, 1980. 


\section{JOSÉ ANTONIO PÉREZ BOWIE}

una herencia grandiosa:

sostenedla.

Amparad ese río de sangre,

sujetad con segura

mano

el tronco de caballos

viejísimos,

pero aún poderosos,

que arrastran con pujanza

el fardo de los siglos

pasados.

A ti,

mi leal amigo,

compañero de armas,

escudero,

sostén de nuestra gloria,

joven alférez de mis escuadrones

de arcángeles vestidos de accituna,

sé que no es necesario amonestarte

con seguir siendo fuego y hierro

basta.

Fuego para quemar lo que florece.

Hierro para aplastar lo que se alza4.

Tras el yo explícito, que mimetiza el discurso reaccionario de los vencedores de la contienda civil con su retórica vacua y su anatema contra cualquier conato de rebeldía, se detecta con facilidad la imagen de un yo implícito situado en los antípodas de la ideología sustentada por un mensaje que se autorridiculiza en su propia obviedad y simplismo.

\section{Yo difunto}

Esta variante de primera persona ajena se manifiesta en aquellos poemas en los que la voz del hablante lírico se presenta como venida de más allá de la muerte; no es el caso de la poesía funcraria tradicional en la que el autor encomienda la responsabilidad de la enunciación a un personaje fallecido, apoyándose en la convención del epitafio como mensaje póstumo del difunto (por ejemplo, el soneto de Garcilaso titulado "Para la sepultura de Don Hernando de Guzmán"); ni tampoco resulta equiparable al procedimiento que hemos descrito más arriba bajo la denominación de "yo histórico", pues aquí el hablante lírico se presenta como un desdoblamiento del yo autorial explicable a partir de las técnicas alucinatorias a las que la poesía contemporánea recurre en ocasiones para cuestionar la aparente estabilidad y coherencia de la realidad (CAÑ $A S, 1986: 45-60)$. En los casos a que me refiero, ésta es experimentada por el yo lírico desde la perspectiva de la muerte, lo que implica la pérdida del sentido del mundo circundante y la necesidad de replantearse todos los valores que lo sustentan; este procedimiento supone a la vez un tour de force al que se somete a la comunicación poemática colocándola en una situación límite que conlleva su propio cuestiona-

4.- Palabra sobre palabra, Barcelona, Seix Barral, 1986 
miento. En los libros de José Hierro se pueden encontrar algunos poemas que ilustran a la perfección el uso de este tipo de primera persona ajena y que han sido comentados de manera brillante por Dionisio Cañas, quien los explica como "intentos de objetivar la angustia existencial, de sentir la esencial heterogeneidad del ser que añora una homogeneidad perdida a través del conocimiento y de su experiencia como ser vivo" (CAÑAS, 1986: 58). Véanse estos versos procedentes del poema "Mis hijos me traen flores de plástico":

$\Lambda q u i ́$ me dejan bajo tierra. Es una tarde de febrero.

Todo es negro cuando se van. Y mudo. Se ha extinguido

esa música gris que antes sonaba.

También el tiempo se ha borrado, y su sufrimiento,

de mi cuerpo. Ya el sufrimiento y el tiempo

van deshaciendo poco a poco lo que fue,

y tuvo fe y desánimo, fantasía y amor.

¡Qué pequeño es ahora, a esta distancia

absoluta, $\mathrm{cl}$ afán diario! ¡Qué pequeño lo grande,

lo grande aquello! ¡Qué pequeñas las iras

ante los hombres y sus actos! 5 .

El mismo procedimiento de encomendar la enunciación a un yo difunto lo vemos empleado en el poema de José Ángel Valente "El crimen", si bien con un tono decididamente irónico que lo sitúa en los antípodas de los textos de Hierro: la contemplación de la realidad circundante desde el más allá de la muerte es sometida ahora a un distanciamiento de innegable base lúdica que borra por completo cualquier rastro del intenso dramatismo que impregnaba el poema anterior (reproduzco los fragmentos inicial y final):

Hoy he amanecido

como siempre, pero

con un cuchillo

en el pecho. Ignoro

quién ha sido,

y también los posibles

móviles del delito.

Estoy aquí

tendido

y pesa vertical

el frío.

He sido asesinado.

(Descarto la posibilidad del suicidio.)

Por mi parte no tengo

nada que declarar.

Se busca al asesino;

sin embargo,

tal vez no hay asesino,

aunque se enrede así el final de la trama.

Sencillamente yazgo

5.- Libro de las alucinaciones, Madrid, Cátedra, 1986. 


\section{JOSÉ ANTONIO PÉREZ7. BOWIE}

aquí, con un cuchillo...

Oscila, pendular $\mathrm{y}$

solemne, el frío.

No hay pruebas contra nadie. Nadie

ha consumado mi homicidio ${ }^{6}$.

Otro interesante ejemplo del uso de yo difunto lo encontramos en el poema de Jaime 'Gil de Biedma titulado "Después de la muerte de Jaime Gil de Biedma" (incluido significativamente en el libro Poemas póstumos); sin embargo, en él, el cmpleo del procedimiento se presenta con una complejidad que lo diferencia de los casos hasta ahora considerados: el difunto no es aquí exactamente el sujeto de la enunciación, sino el destinatario de la misma; con la particularidad de que ese personaje es una ficcionalización del yo real, de quien el sujeto enunciador del poema (al que cabe concebir como otra proyección actual de ese yo) se distancia ubicándolo en un tiempo ya definitivamente ido (transcribo los versos finales):

Yo me salvé escribiendo

después de la muerte de Jaime Gil de Biedma.

De los dos eras tú quien mejor escribía.

Ahora sé hasta que punto tuyos eran

el deseo de ensueño y la ironía,

la sordina romántica que late en los poemas

míos que yo prefiero, por ejemplo en Pandémica...

A veces me pregunto

cómo será sin ti mi poesía.

Aunque acaso fui yo quien te enseñó.

Quien te enseño a vengarte de mis sueños, por cobardía, corrompićndolos?

Son raras otras manifestaciones de primera persona ajena que puedan considerarse, como las revisadas, procedimientos evidenciadores de la ficcionalidad de la comunicación poemática; podría añadirse, si acaso, la utilización que Gloria Fuertes hace de Dios como yo explícito en algunos de sus poemas: "Dios llama al fontanero" y "Ahora habla Dios", ambos de indudable carácter irónico. No es éste, sin embargo, el caso de algunos de los (raros) poemas contemporáneos en que un animal u objeto inanimado figura como sujeto de la enunciación, ya que tal eventualidad es asumible por el lector mediante la presuposición de una metáfora implícita en la estructura profunda del enunciado y formulable en estos términos: $A$ (yo implícito $)=B$ (yo explícito-animal u objeto inanimado) quien diría $C$ (enunciado). El riesgo de fracaso de la comunicación que entrañaba la dificultad de construir el yo implícito a partir del explícito queda, así, eliminado, con lo que ninguno de tales poemas implica cl cuestionamiento de su propio discurso ni la subsiguiente puesta en evidencia de la ficcionalidad. Léanse, por ejemplo, poemas como "Ruedo" o "Al quiebro", de Luis López Álvarez, en los que el sujeto de la enunciación es el toro".

6.- Punto cero, ed. cit.

7.- En S. Mangini, Gil de Biedma, Madrid, Júcar, 1980.

8.- Obras incompletas, Madrid, Cátedra, 1985.

9.- Cómputo (1952-1982), Barcelona, Plaza y Janés, 1985. 


\section{TIPOLOGÍA DE LOS PROCEDIMIENTOS METAFICCIONALES EN LA LIÍRICA}

\section{b) Ficcionalización del yo real}

El enunciado poemático figura puesto en boca de un personaje cuyo nombre coincide con el del autor empírico; en otras palabras, el poeta se ficcionaliza como personaje, apareciendo, con su propio nombre, como responsable o destinatario de la enunciación. Se trata, evidentemente (aunque quienes defienden la identificación del poeta con el hablante lírico lo puedan considerar como una prueba de sus asertos), de una ruptura de las convenciones por las que se rige la comunicación lírica y que tienden a preservar la frontera existente entre la voz que habla desde el pocma (personaje atemporal generado por el propio discurso) y la del autor en cuanto ser inmerso en el tiempo. Mediante tal procedimiento, el autor pretende trastocar las fronteras entre realidad y ficción y se introduce en el universo de esta última como personaje, en un juego del que existen también conocidos ejemplos en el ámbito de la ficción narrativa: Unamuno o Borges, entre otros. Los textos que mejor nos pueden servir para ilustrar el uso de este procedimiento en la lírica son, sin duda, los poemas de Gil de Biedma "Contra Jaime Gil de Biedma" y el arriba reproducido "Después de la muerte de Jaime Gil de Biedma". En el primero de ellos, el interlocutor a quien el hablante lírico se dirige es el propio poeta, ficcionalizado como su otro yo, como cl lado negativo de su personalidad; $\mathrm{cl}$ discurso se desarrolla en un tono irónico derivado de la propia estructura del poema, que se basa en un juego de engaño-desengaño en el que el lector no descubre hasta cl final el desdoblamiento, al saber que el amante increpado no es una tercera persona sino la proyección del sujeto hablante:

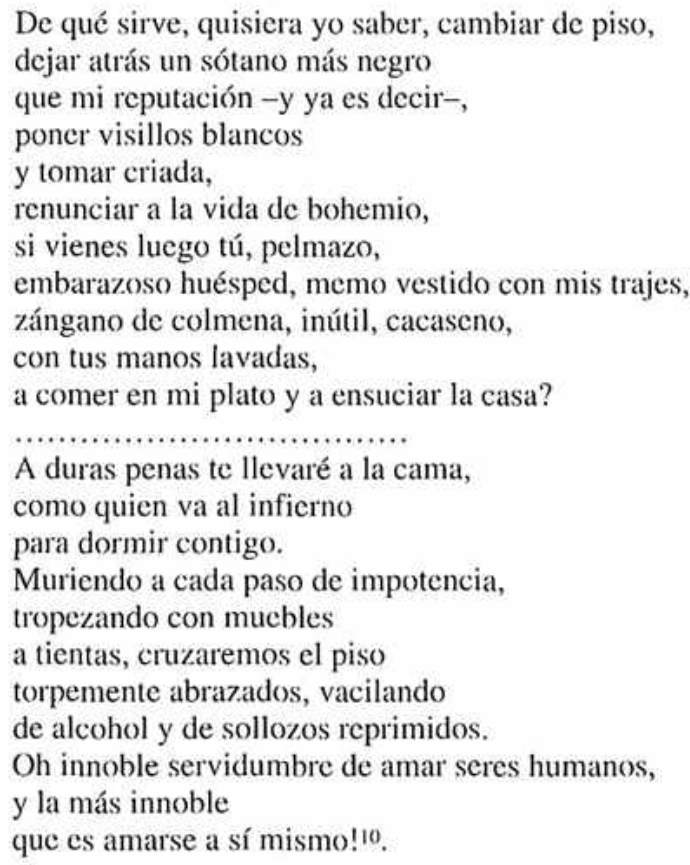

En el texto que vimos anteriormente, la muerte del personaje (ficción del yo autorial) al que el hablante lírico interpela es una muerte simbólica: el personaje -el Jaime Gil de

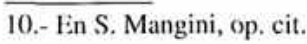




\section{JOSÉ ANTONIO PÉREZ BOWIE}

Biedma anterior- no existe ya porque el paso del tiempo ha producido su metamorfosis en un hombre nuevo, el hablante lírico, desde cuya perspectiva se articula el discurso".

Otro ejemplo de este desdoblamiento, que se manifiesta en la aparición como personaje en el poema del yo autorial, lo tenemos en el texto "Las nubes", de José Hierro, aunque aquí sin la complejidad de los precedentes, pues se trata de un simple caso de desdoblamiento provocado con fines distanciadores para neutralizar la carga de sentimentalidad que hubicra conllevado la enunciación en primera persona:

Inútilmente interrogas.

Tus ojos miran al ciclo.

Buscas detrás de las nubes,

huellas que se llevó el viento.

Buscas las manos calientes,

los rostros de los que fueron,

el círculo donde yerran

tocando sus instrumentos.

Inútilmente interrogas

desde tus párpados ciegos.

¿Qué haces mirando a las nubes,

José Hierro?'12.

\section{c) Denuncia de la ficcionalidad de los personajes poemáticos}

La transgresión de los convencionalismos por los que se rige la comunicación lírica puede producirse tanto en el sentido que acabamos de ver (ficcionalización de lo real) como en el inverso; es decir, mediante la denuncia del carácter irreal del universo poemático y la reafirmación de la entidad puramente imaginaria-seres de papel-de sus criaturas. La ilusión de realidad que el mantenimiento de las convenciones hace posible resulta, así, destruida, quedando de manifiesto una vez más el estatus de representación que posee la comunicación lírica. El siguiente texto de Luis García Montero, en donde la voz. del hablante lírico denuncia la fragilidad de su propia existencia y de la de su interlocutor, es un ejemplo significativo de este procedimiento:

Recuerda que tú existes tan sólo en este libro, agradece tu vida a mis fantasmas, a la pasión que pongo en cada verso para recordar el aire que respiras, la ropa que te pones y me quitas, los taxis en que viajas cada noche, sirena y corazón de los taxistas, las copas que compartes por los bares con las gentes que viven en sus barras.

11.- En realidad, todo el libro Poemas póstumos está concebido desde el conflicto entre el yo joven, que se resiste a desaparecer, y el yo adulto (MANGINI, 1980: 108-109).

12.- Cuanto sé de mí, Barcelona, Seix Barral, 1974. 
Recuerda que mi reino son las dudas de esta ciudad con prisa solamente, y que la libertad, cisne terrible, no es el ave nocturna de los sueños, sí la complicidad, su mantenerse herida por el sable que nos hace sabernos personajes literarios, mentiras de verdad, verdades de mentira.

Recuerda que yo existo porque existe este libro, que puedo suicidarnos con romper una página'3.

\section{d) El discurso lírico, conferidor de realidad}

Paradójicamente, y en contraste con el procedimiento precedente, encontramos algún caso en el que la sola mención de la persona desde el poema se convierte en justificación de éste. El discurso del sujeto de la enunciación funciona como una ejemplificación de la teoría platónica, según la cual nombrar es conferir existencia, y el objetivo perseguido no es entablar comunicación con el destinatario explícito, sino tan sólo nombrarlo y, consiguientemente, dotarlo de realidad. Es el caso del poema "Para Clara", de Antonio Colinas, en el que el hablante lírico, ante la insuficiencia de las palabras para dirigirse a su interlocutor-presumiblemente la amada-confiere a éstas la mera función de configurar el marco que rodea el nombre de aquél, nombre que constituye no sólo el título sino la justificación y el elemento central del poema:

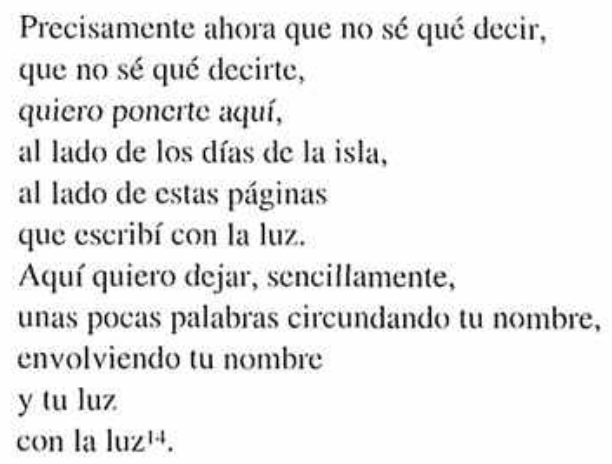

Este tipo de texto se mueve ya en el ámbito de la llamada poética del silencio, en donde el poema se cuestiona su propio material expresivo y se enfrenta con el no decir como límite de la escritura; ésta es una de las manifestaciones de la autorreflexividad que impregna a gran parte de la lírica contemporánea en la que el poema se tiene a sí mismo -y consiguientemente a sus posibilidades expresivas-como centro temático.

13.- Diario cómplice, Madrid, Hiperión, 1987.

14.- Astrolabio, Madrid, Visor, 1979. 


\section{JOSÉ ANTONIO PÉREZ BOWIE}

\section{e) Apelación al tú empírico del lector}

Se trata de un nuevo caso de transgresión metaficcional consistente en traspasar las fronteras que delimitan los ámbitos de la comunación intratextual (personajes explícitos $\mathrm{c}$ implícitos) y extratextual (personajes reales): el hablante lírico no se dirige a un ser de su propia naturalcza e inscrito, por tanto, en el ámbito comunicativo ficcional del poema, sino al presunto lector real del mismo. El cjemplo que nos puede servir mejor para ilustrar este procedimiento es el poema de Mariano Roldán titulado "La lectura"; su enunciado está concebido como una apelación a un destinatario al que se supone enfrentado a la propia materialidad del texto -su expresión gráfica- y al que se desafía a penetrar en la significación que se oculta tras la misma:

¡Mirad, mirad, mirad bien! Pero ¿no veis cómo saltan, no veis cómo van y vienen, no veis cómo se adelantan? No me digáis que veis sólo palabras, sólo palabras impresas.

¿No suena el aire, no canta el río que canta, no transparece la luz que en la palabra se ampara?'5.

Nos encontramos ante uno de los numerosos textos líricos contemporáneos en los que el cuestionamiento de la propia escritura (manifiesta aquí en la simultancidad de producción y recepción) se convierte en referente del poema. Con ello entramos en el sexto y último apartado de esta tipología:

\section{f) Mostración del poema en su hacerse}

En el momento en que el poema se nos presenta autodesignándose, con la categoría de objeto autónomo, el propio acto de la escritura puede llegar a convertirse en centro temático, con lo que el texto no nos es entregado como un producto concluido sino mostrado como un devenir; el objetivo que se persigue es, entonces, llamar la atención sobre la propia escritura como proceso que ha conducido a aquél. El procedimiento en sí no es nada novedoso pues podrían citarse antecedentes ilustres como "Un soneto me manda hacer Violante", de Lope de Vega; la originalidad en los líricos contemporáneos radica en utilizar ese protagonismo del proceso de gestación del poema para llevar a cabo una reflexión sobre las dificultades de la escritura y la escasa ductilidad del material lingüístico, con lo que la mayoría de los textos construidos sobre este procedimiento entrarían, además de en la categoría de metaficcionales, en la de metapoéticos. Leamos, como ilustración, el poema "Sub nocte" de Jaime Siles:

Y medejas aquí, frente al lenguaje,

en una sola y misma vastedad

de tinta extensa que me borra,

15.- Citado por López Casanova-Alonso: P'oesía y novela, Valencia, Bello, 1982, pág. 152. 


\section{TIPOLOGÍA DE I.OS PROCEDIMIENTOS METAFICCIONALES EN LA LÍRICA}

de tatuada noche que me anula, porque nada en ti suena, teclado, tacto, tatuaje. Todo: correspondencias lejos apagadas, letra invisible, cero

del principio nocturno $y$ del final ${ }^{16}$.

Esa mostración del devenir del cual resulta el texto puede tener como objetivo no sólo el poema sino el complejo supratextual más amplio -el libro-donde aquél se inserta constituyendo un jalón más de ese devenir. Así lo vemos en el siguiente poema de Agustín Delgado, titulado "Va creciendo este libro":

Va creciendo este libro.

Y día llegará en que será alto

como adolescente que surge de larga enfermedad.

Dejarán tus ojos caer

una mirada de honda turbación.

Desgarbado, dócil

va creciendo este libro

que alguien, otro, escribe

despreocupadamente, con la ligereza

de quien, lejos, no repara en

ese perfume cruel, esa fiebre tibia

que cada página lleva17.

Finalizo con este último ejemplo esta revisión de los procedimientos con que la lírica contemporánea realza el carácter de enunciación enunciada de su discurso. Si bien varios de ellos son detectables a lo largo de la historia literaria, lo específico de nuestra época es su utilización sistemática, inscrita en un tratamiento irónico que persigue la puesta en evidencia de lo que la comunicación lírica tiene de representación. Ello conlleva un lógico proceso de desacralización de la poesía, que, paradójicamente, en lugar de producir como resultado la trivialidad de su decir, ha abierto las puertas a una reflexión profunda sobre el ser del lenguaje, sobre sus limitaciones, pero, a la vez, también sobre sus posibilidades de instrumento comunicativo por encima de las pautas de su utilización racional ${ }^{18}$. De ahí que la autorreferencialidad - el poema como tema del poema-constituya, como apuntaba al principio, la otra de las constantes más perceptibles de la poesía de nuestra época.

16.- Fin G.L. Solner, Poesía española hoy, Madrid, Visor, 1982.

17.- De la diversidad (Poesía 1965-1980), Madrid, Hiperión, 1983.

18. - Luis García Montero, uno de los jóvenes valores de nuestra lírica actual, resume lúcidamente esta cuestión con las siguientes palabras: "Cụando se acepta el distanciamiento como método de trabajo el poema deja de ser la respuesta sensible a una motivación empírica (o al menos deja de ser sólo eso). Para darse totalmente a un discurso, para imprimirle un sentido nuevo hay que verlo primero desde lejos. $Y$ esto es importante, casi definitivo, puesto que sólo cuando uno descubre que la poesía es mentira en el sentido más teatral del término- puede empezar a escribirla de verdad" (GARCÍA MONTERO, 1983:14). 


\section{JOSÉ: ANTONIO PÉRI:Z BOWIE}

\section{Referencias bibliográficas}

BOUSOÑO, C., (1983), Estudio preliminar a G. Carnero: Ensayo de una teoría de la visión (Poesía 1966-1977), Madrid, Hiperión.

CALINESCU, M., (1991), Cinco caras de la modernidad, Madrid, Tecnos.

CAÑAS, D., (1986), Introducción a José Hierro, Libro de las alucinaciones, Madrid, Cátedra.

GARCÍA MONTERO, L., (1983), La otra sentimentalidad, Granada, Don Quijote.

HAMBURGER, K., (1986), Logique des genres littéraires, Paris, Scuil.

LEVIN, S., (1987), "Consideraciones sobre qué tipo de acto de habla es un poema", en Mayoral, Pragmática de la commicación literaria.

LEVIN, Y., (1979), "La poesia lirica sotto il profilo della comunicazione", en AA.VV., L.a semiotica nei paesi slavi, Milano, Feltrinelli.

MANGINI, S., (1980), Gil de Biedma, Madrid, Júcar.

MAYORAL, J. A., (1987), Pragmática de la comunicación literaria, Madrid, Arco.

OOMEN, U., (1987), "Sobre algunos elementos de la comunicación poética", en Mayoral, Pragmática de la commicación literaria.

PÉREZ BOWIE, J. A., (1993), "La primera persona ajena en los sonetos funerarios y mitologicos del Siglo de Oro", en Estado actual de los estudios sobre el Siglo de Oro (Actas del II Congreso Internacional de la AISO), Salamanca, Universidad.

POZUELO, J. M.", (1991), "Lirica e finzione (in margine a Ch. Bateux)", Strumenti Critici, $X V, 1$, gennaio.

REISZ DE RIVAROLA, S., (1989), Teoria y análisis del texto literario, Buenos Aires, Hachelte.

SCHMIDT, S., (1987), "La comunicación literaria", en Mayoral, Pragmática de la commicación literaria.

VILlAnUEVA, D., (1992), Teorías del realismo literario, Madrid, Instituto de Fspaña-Espasa Calpe. 